\title{
FASILITAS INTERAKSI LANSIA DAN MILENIAL
}

\author{
Aiko Putri Marui ${ }^{1)}$, Rudy Surya ${ }^{21}$ \\ 1)Program Studi S1 Arsitektur, Fakultas Teknik, Universitas Tarumanagara, aikomarui97@gmail.com \\ 2) Program Studi S1 Arsitektur, Fakultas Teknik, Universitas Tarumanagara, rs88seb@gmail.com
}

\begin{abstract}
Abstrak
Third Place merupakan sebuah kebutuhan tambahan yang dibutuhkan masyarakat Meruya Selatan. Penduduk milenial dan lansia di Meruya Selatan merupakan jumlah penduduk yang tertinggi disana. Maka dari itu proyek ini diutamakan untuk mereka. Dan juga terdapat permasalahan hubungan antara lansia dan milenial yang renggang, karena perbedaan pola pikir dan kebiasaan. Maka dari itu proyek yang berada di Jalan Meruya Utara ini bertujuan untuk menyediakan berbagai fasilitas yang dapat mereka gunakan bersama-sama dan dapat menciptakan kembali hubungan yang erat antara mereka selain itu juga proyek ini tidak hanya menerima kaum milenial dan lansia tapi juga semua orang dari berbagai golongan sosial dan umur. Selain menjadi tempat berkumpul juga proyek ini menyediakan berbagai workshop atau kelas-kelas agar mereka dapat melakukan aktivitasaktivitas bersama-sama dan dapat terbentuk komunikasi karena terjadinya aktivitas mengobrol ataupun bertukar pikiran. Selain itu juga disediakan tempat untuk mereka dapat berolahraga untuk kepentingan Kesehatan lansia maupun milenial. Metode yang digunakan dalam penulisan ini adalah dengan melakukan studi Kawasan, Pustaka. Berdasarkan hasil survei lapangan dan literatur dihasilkan kesamaan-kesamaan aktivitas kaum lansia dan milenial yang diharapkan dapat menjadi aktivitas bersama mereka. Hasil kajian tersebut dianalisis dan disintesiskan dalam wujud perancangan fasilitas interaksi kaum lansia dan milenial di Meruya Selatan.
\end{abstract}

Kata kunci: lansia; milenial; tempat ketiga

\begin{abstract}
Third Place is an additional requirement needed by the people of South Meruya. Millennial and elderly population in South Meruya is the highest population there. Therefore this project is prioritized for them. And there are also problems with the relationship between the elderly and tenancy that are tenuous, due to differences in mindset and habits. Therefore the project which is located on Jalan Meruya Utara aims to provide various facilities that they can use together and can re-create a close relationship between them but this project also not only accepts millennials and the elderly but also all people from various social and age. In addition to being a gathering place, this project also provides various workshops or classes so that they can carry out activities together and communication can be formed because of the activity of chatting or exchanging ideas. It also provided a place for them to exercise for the benefit of elderly and millennial health. The method used in this paper is to study the Regions, Library. Based on the results of field surveys and literature, the similarities in the activities of the elderly and millennials are expected to be their joint activities. The results of the study were analyzed and synthesized in the form of designing an elderly and millennial interaction facility in South Meruya.
\end{abstract}

\section{Keywords: elderly; millennials; third place}




\section{PENDAHULUAN}

\section{Latar Belakang}

Daerah Khusus Ibu Kota Jakarta merupakan ibu kota negara Indonesia. Jakarta merupakan satu-satunya kota di Indonesia yang memiliki status setingkat provinsi yang terletak di pesisir bagian barat laut Pulau Jawa. Kota Jakarta sendiri memiliki luas sekitar $661,52 \mathrm{~km}^{2}$ dengan kepadatan penduduk 10,5 juta jiwa (2019). Kepadatan penduduk ini menyebabkan terjadinya kepadatan pada urban. Pertumbuhan penduduk masih terus berkembang karena beberapa sebab salah satunya adalah pengaruh baby boomers di tahun 1950. Hal tersebut menyebabkan berkembangnya jumlah penduduk yang tidak dapat dihentikan.

Kondisi Jakarta yang sudah sangat padat membuat keadaan yang kurang nyaman bagi penghuni Jakarta sendiri. Lahan yang sudah sangat kurang menyebabkan banyak masyarakat yang kekurangan ruang sosial terbuka. Sehingga menyebabkan sulitnya maysarakat untuk mencari tempat untuk melakukan personal experienced, tempat untuk saling bertukar informasi dalam bentuk fisik, tempat yang berfungsi dan dapat memenuhi kebutuhan mereka, dan sekaligus fun. Di wilayah Jakarta Barat memiliki tingkat kepadatan penduduk yang paling tinggi. Sehingga warga di wilayah ini membutuhkan ruang sosial terbuka. Di Jakarta Barat sendiri menurut data penduduk di BPS 2019 kalau kecamatan Kembangan merupakan kecamatan yang memiliki tingkat kepadatan yang paling rendah di banding kecamatan lainnya $(12.035 \mathrm{jiwa} / \mathrm{km})$ dengan luas wilayah yang paling luas $\left(24,16 \mathrm{~km}^{2}\right)$. Kecamatan Kembangan ini terdiri dari 6 kelurahan, 62 RW dan 610 RT. Hal ini memberikan kemungkinan lahan yang bisa di gunakan lebih banyak tersedia.

Berdasarkan data BPS 2019 wilayah Kelurahan Meruya Selatan merupakan kecamatan yang memiliki luas yang kedua terkecil di bandingkan dengan kecamatan lainnya $\left(3,61 \mathrm{~km}^{2}\right)$ dengan tingkat kepadatan paling rendah yaitu $8.938 \mathrm{jiwa} / \mathrm{km}$, didominasi dengan zona hunian dan beberapa zona campuran dan zona pelayanan umum dan sosial. Dari data BPS (2011 - 2019) perkembangan area public / third place di kelurahan ini sangat rendah dibandingkan dengan kelurahan lainnya, sehingga pilihan tempat untuk warga kelurahan meruya selatan melakukan kegiatan untuk bersosialisasi menjadi sangat minim. Selain itu di Kelurahan Meruya Selatan ini jumlah lansia (lanjut usia) tiap tahunnya naik dengan drastis.

\section{Rumusan Permasalahan}

- Program kegiatan seperti apa yang diperlukan kaum lansia dan milenial warga Meruya Selatan dalam berinteraksi bersama-sama sehingga menciptakan hubungan yang akrab dan harmonis?

- Bagaimana perancangan wadah berinteraksi yang sesuai dan mampu menjawab kebutuhan berinteraksi bersama dari kaum lanjut usia dan milenial warga Meruya Selatan?

\section{Tujuan}

Tujuan dari perancangan ini yaitu untuk memberikan dukungan kepada komunitas-komunitas ataupun individu dalam meningkatkan sosialisasi dalam bentuk fisik, selain itu karena banyaknya lansia di kelurahan Meruya Selatan ini maka memberikan wadah yang memadai untuk para masyarakat lansia (lanjut usia) dan memiliki fasilitas untuk mereka dapat beraktifitas dan bertemu dengan orang-orang yang seumuran, dewasa, ataupun anak-anak agar dapat meningkatkan kualitas dan semangat para lansia (lanjut usia) karena merasa sudah tua dan tidak tahu untuk melakukan apa. Selain menyediakan tempat sosialisasi juga menyediakan fasilitas yang di butuhkan masyarakat seperti misalnya tidak adanya tempat atau wadah untuk lansia (lanjut usia) berolahraga/gym yang ramah terhadap lansia dan kebutuhan fasilitas lainnya yang dapat di kaitkan dengan masyarakat muda sehingga dapat meningkatkan hubungan sosialisasi antara lansia (lanjut usia dan milenial. 


\section{KAJIAN LITERATUR}

\section{Kawasan Meruya Selatan}

Kawasan yang dipilih berada di Kelurahan Meruya Selatan, Kecamatan Kembangan, Jakarta Barat. Dari data kependudukan Jakarta Barat (data BPS 2018) kalau lusa wilayah Meruya Selatan adalah $2,80 \mathrm{~km}^{2}$ dengan populasi penduduk 38.339 jiwa. Kawasan ini didominasi dengan Kawasan permukiman dan ruko. Warga di Meruya Selatan sendiri ada yang bekerja di Jakarta Pusat ataupun di Meruya Selatan. Dari hasil data BPS (2017-2018) ternyata memang peningkatan jumlah warga yang masuk dalam kategori lansia naik drastis tiap tahunnya sekitar 50\%. Dari data BPS diatas dapat dilihat kalau penduduk yang berumur 35-49 tahun merupakan jumlah penduduk yang paling banyak yaitu penduduk yang berada di usia produktif (bekerja). Lalu untuk usia lebih dari 60 tahun mengalami peningkatan yang cukup signifikan dari tahun 2017 menuju 2018.

\section{Kajian Third Place}

Berdasarkan buku The Great Place (Oldenburgh, 1989), bahwa The Third Place adalah tempat orang berkumpul selain bekerja atau di rumah. Inggris memiliki pub, Prancis memiliki cafe, dan Austria memiliki kedai kopi. Sebuah tempat dikatakan sebagai Third Place ketika (Oldenburgh, 1989) :

- Neutral, orang bisa datang dan pergi tanpa penalti. Jika Anda tidak pergi ke tempat ketiga Anda selama beberapa hari atau minggu, pengembalian Anda disambut dengan minat dan antusiasme.

- Level, perbedaan status yang sangat penting di tempat lain tidak relevan. Dan tidak ada yang memainkan tuan rumah di tempat ketiga.

- Conversation, kegiatan utama di tempat ketiga, dan salah satu dari beberapa cara untuk menyinggung orang lain yang hadir adalah menjadi membosankan.

- Accessible, tempat ketiga dapat diakses, artinya mereka memiliki jam yang panjang dan mudah dijangkau.

- Regular, tempat ketiga memiliki pengunjung tetap. Memang, pelanggan tetap menentukan tempat ketiga, tetapi orang baru diterima, tidak secara otomatis tetapi sering dengan mudah.

- A Low Profile, tempat ketiga secara fisik sederhana dan bersahaja.

- Playful, suasana dominan dari third place adalah menyenangkan.

\section{Lansia}

Menurut World Health Organisation (WHO) yang dimaksud dengan lansia (lanjut usia) adalah seorang manusia yang telah memasuki usia umur 60 tahun ke atas. Lansia sendiri merupakan bagian dari kelompok tahapan terakhir dari suatu fase kehidupan manusia. Kelompok lansia akan mengalami proses yang disebut Aging Process (proses penuaan). Lalu menurut UU no. 4 tahun 1965 definis lansia adalah orang yang mencapai umur 55 tahun dan tidak berdaya mencari nafkah sendiri untuk keperluan sehari-harinya dan menerima nafkah dari orang lain (Wahyudi,2000), sedangkan menurut UU no.12 tahun 1998. Beberapa karakteristik lansia adalah rasa ingin tahu, kreativitas, gampang putus asa, dll (Butler R.N. \& M.L.Lewis, 1983). Untuk kebutuhan lansia sendiri lansia membutuhkan rasa nyaman untuk diri mereka sendiri dan nyaman dengan lingkungan yang ada (Setiati, 2000). Untuk masalah-masalah yang biasa dihadapi oleh lansia adalah adanya perubahan mood yang signifikan.

\section{Milenial}

Istilah milenial pertama kali dicetuskan oleh William Strauss dan Neil dalam bukunya yang berjudul Millennials Rising: The Next Great Generation (2000). Istilah ini diciptakan pada tahun 1987, saat anak-anak yang lahir pada tahun 1982 masuk ke pra-sekolah, mereka mulai dipanggil kaum milenial saat orang-orang yang lulus sekolah menengah atas ditahun 2000. 
Selain itu juga disebutkan Millennial Nusantara adalah masyarakat yang lahir ditahun 19812000 (Ali \& Purwandi, 2017).

Untuk karakteristik milenial sendiri salah satunya yang paling utama adalah meningkatnnya penggunaan dan semakin dekatnya milenial dengan komunikasi dalam bentuk media dan teknologi digital. Selain itu karakteristik milenial dalam buku Generasi Millenials Indonesia karakteristik-karakteristik milenial yaitu ingin serba cepat, mudah berpindah pekerjaan dalam waktu singkat, kreatif, dinamis, dekat dengan media sosial (Sebastian, 2016). Untuk kebutuhan milenial bekerja tidak hanya sekedar kebutuhan materi tapi juga mengejar tujuan, selain itu bekerja dengan tujuan untuk menambah ilmu, skill, sudut pandang, dll (Gallup, 2016). Yang terakhir masalah yang dihadapi milenial adalah menurunnya jiwa idealism, patriotism, nasionalisme dikalangan masyarakat milenial, Belum seimbangnya jumlah milenial dengan fasilitas Pendidikan dan pembinaan yang tersedia (formal ataupun nonformal), adanya perbedaan pendapat dan system nilai antara generasi milenial dan generasi sebelumnya.

\section{METODE}

Dalam menyelesaikan proyek, diperluka tahap-tahap penelitian untuk menciptakan desain yang tepat dan bermanfaat untuk pengguna dan pengunjung. Maka dari itu metode yang dilakukan adalah:

\section{- Pengumpulan Data}

Studi literatur ini dilakukan dengan perolehan data berdasarkan teori, kajian, dan sumber-sumber literatur yang lain. Selain itu juga ada studi preseden untuk memahami proyek-proyek lain yang serupa dan dilakukan perbandingan.

- Survey Lapangan

Survey lapangan dilakukan untuk mencari data tapak yang lebih tepat dan juga untuk melihat langsung lokasi proyek dengan nyata.

- Wawancara Warga Sekitar

Wawancara langsung dilakukan untuk menanyakan kebeberapa warga mengenai apa yang mereka butuhkan dan apakah fasilitas yang akan disediakan akan berfungsi dan sesuai dengan kebutuhan mereka.

- Analisis

Analisi merupakan hasil kesimpulan dari perolehan data, lapangan, dan wawancara yang telah didapatkan

- Pendekatan ke Third Place

Pendekatan dilakukan dengan menghasilkan aktifitas dan fasilitas yang dibutuhkan warga dan juga bisa memenuhi kriteria third place sendiri

- Hasil Desain

Hasil desain didapatkan dari merangkum semua hal diatas dan menghasilkan sebuah proyek bangunan dengan konsep, tema, dan bangunan yang sesuai

\section{DISKUSI DAN HASIL}

\section{Analisis Tapak}

Lokasi proyek berada diantara Lalan Meruya Selatan dan Jalan K.H. Aja. Lokasi yang dipilih berdasarkan kriteria tapak yang diinginkan seperti letak yang strategis sesuai dengan sasaran dan kriteria. Pada lokasi tapak sendiri didominasi dengan zona hunian dan beberapa zona campuran. Lokasi tapak berjarak 247 meter dari pemberhentian busway kantor polisi meruya selatan (Grogol-Meruya). Dari pemberhentian busway menuju tapak dapat di capai dengan berjalan kaki dengan waktu sekitar 10 menit ataupun ojek online sekitar 2-5 menit. Dan didepan tapak terdapat pemberhentian busway, sehinga masyarakat dapat dengan mudah menacapai tapak. 


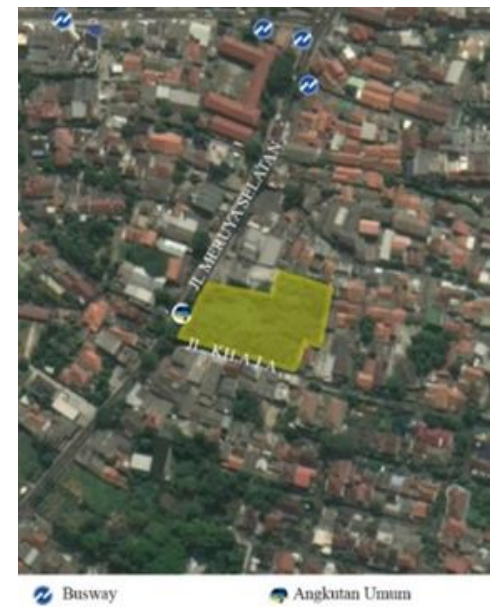

Gambar 1. Lokasi Tapak

Sumber: Googlemaps.com (Modifikasi)

Untuk ukuran tapak memiliki luas $2500 \mathrm{~m}^{2}$ dengan KDB 50, KLB 2, KB 4, KDH 30, dan untuk zona tapak sendiri merupakan zona perkantoran, perdagangan, dan jasa. Sirkulasi kendaraan umum di jalan sekitar tapak pada hari biasa diwaktu siang dan sore sering macet karena jam makan siang dan pulang kantor, lalu di hari libur (weekend) keadaan di sekitar tapak tidak macet, hanya pada sore hari lebih padat disbanding pagi dan siang hari. Lokasi tapak yang terletak dekat dengan rumah warga memudahkan mereka untuk mencapai tapak, selain itu juga terdapat second place disekitar tapak (ruko-ruko) yang secara tidak langsung menjadi permiabiltas pergerakan manusia, hal ini memenuhi syarat akan third place yang harus berhubungan dengan lingkungan sekitarnya.

\section{Program}

Program yang disediakan merupakan hasil dari hasil survei dan mewawancarai warga sehingga program yang disediakan sesuai dengan kebutuhan warga selain itu juga program yang disediakan dapat digunakan dari berbagai kalangan sehingga dapat memenuhi salah satu kriteria dari third place, Program-programnya yaitu:

- Workshop atau kelas (Seperti: Kelas Melukis, Kelas Keramik Tanah Liat, Kelas Musik, Kelas Merangkai dan Menanam).

- Perpustakaan

- Area untuk Olahraga (Senam, Taichi, dan Yoga)

- Fasilitas Publik dan Penunjang (Retail, Foodcourt)

- Kedai kopi (Café)

\section{Zoning}

Bentuk gubahan berawal pada lantai dasar yang dibuat 70\% terbuka untuk area plaza, taman, dan foodcourt, lalu untuk area tertutup merupakan area untuk lobby, lounge, retail, dan cafe. Dan pada lantai dasar juga terdapat 2 jalur akses dari arah jalan meruya utara dan jalur service dari arah JI. K.H. Aja. Area tengah dibuat terbuka tanpa atap dan dinding untuk taman dan plaza. Untuk luasan total pada lantai dasar adalah $785 \mathrm{~m}^{2}$.

Pada lantai dasar ini fasilitas yang disediakan sudah memenuhi beberapa karakteristik third place menurut Ray Oldenburgh yaitu level yaitu terlihat semua orang dapat datang tanpa memandang status, conversation pada area foodcourt atau taman dapat terjadi aktivitas saling berkomunikasi antar individu ataupun kelompok, accessible mudah dicapai warga sekitar maupun bukan warga disana, regular tidak hanya menerima warga sekitar siapapun dapat menikmati fasilitas yang disediakan, dan 
playful yaitu orang-orang dapat bermain di plaza ataupun taman. Lalu pada lantai dua bentuk massa berbentuk $U$ yang terdiri dari kelas-kelas/workshop. Bentuk ini sendiri agar system pencahayaan dapat maksimal masuk ke bangunan. Untuk luasan total pada lantai dua adalah $800 \mathrm{~m}^{2}$.
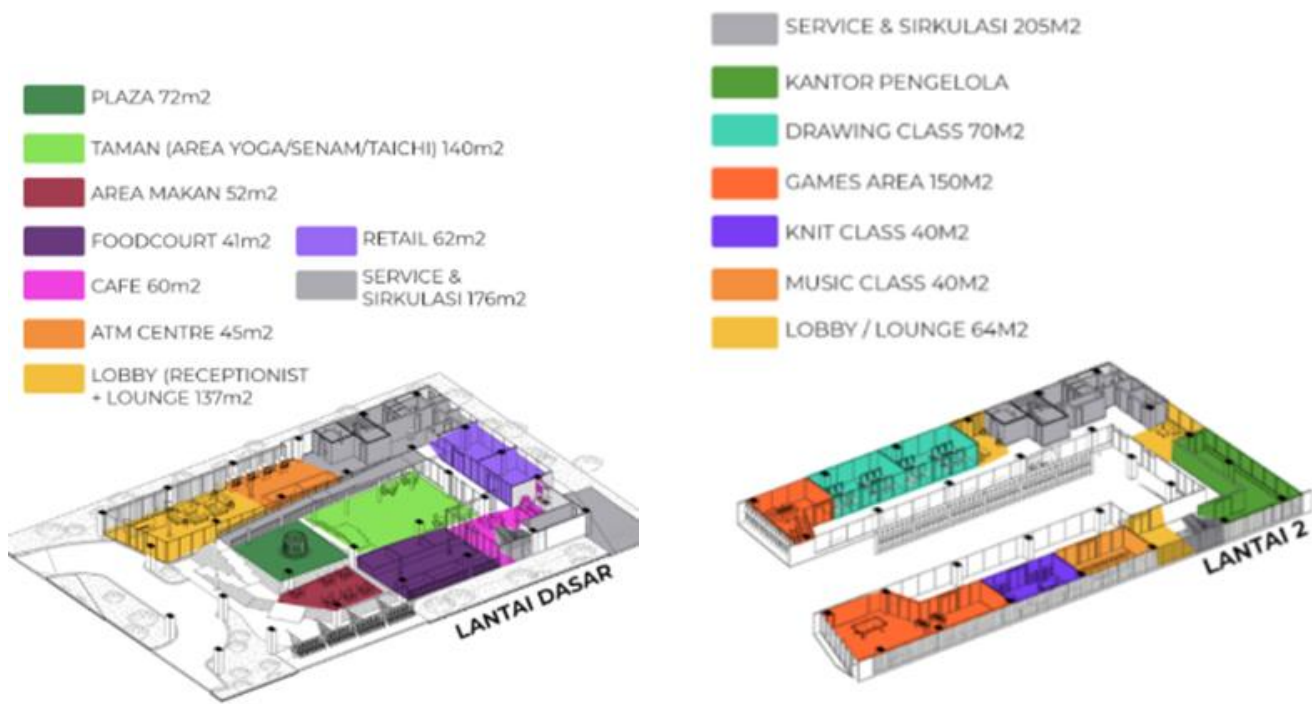

Gambar 2. Zoning lantai dasar (kiri), Zoning lantar dua (kanan)

Sumber: penulis, 2020

Dan pada lantai tiga massa masih sama berbentuk $U$ tapi lebih pendek. Pada lantai ini merupakan lantai untuk perpustakaan, cafe, dan juga ruang serbaguna. Pada area cafe dibuat terbuka sehingga terjadi penghawaan alami pada area ini. Untuk luasan total pada lantai tiga adalah $1065 \mathrm{~m}^{2}$.
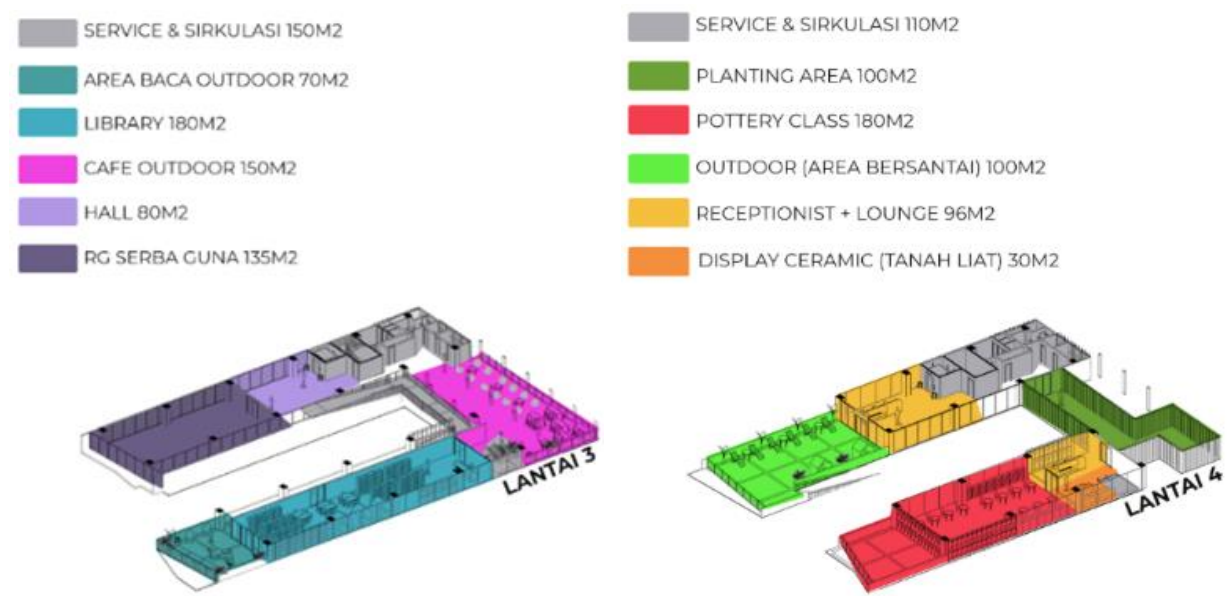

Gambar 3. Zoning lantai tiga (kiri), Zoning lantar empat (kanan) Sumber: penulis, 2020

Dan pada lantai paling atas merupakan area planting class, dan pottery class. Pada lantai ini hampir semua area terbuka kecuali lounge dan pottery class (kecuali area pengeringan). Area dibuat hampir semua terbuka karena kebutuhan akan angin alami cahaya matahari pada planting class sangat dibutuhkan untuk tanaman-tanaman, sedangkan untuk area santai warga membutuhkan area bersantai dengan udara segar dan juga untuk lansia berjemur untuk kesehatan tubuh mereka. Untuk total luasan pada lantai paling atas adalah $616 \mathrm{~m}^{2}$. 


\section{Bentuk}

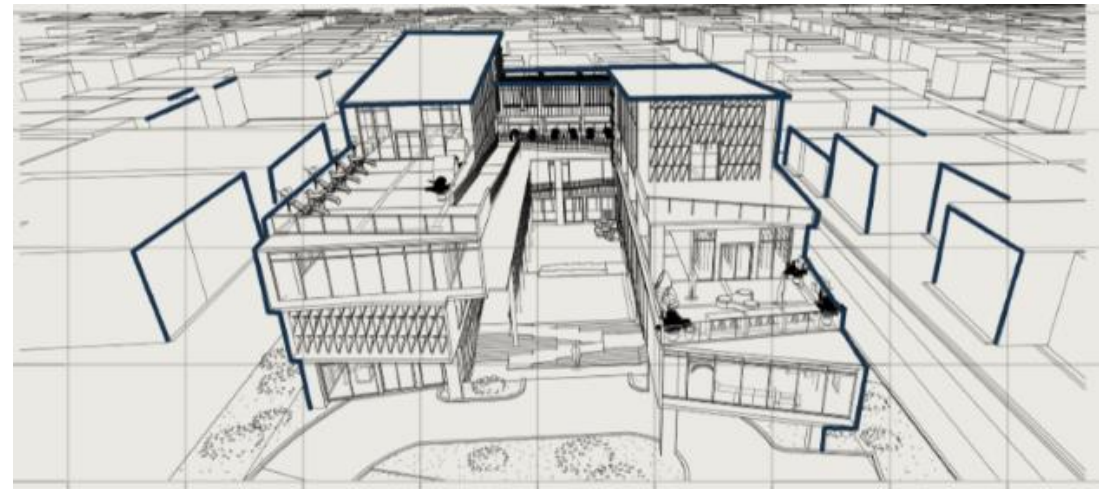

Gambar 4. Bentuk Bangunan

Sumber: penulis, 2020

Bentuk bangunan dibuat dan didesain tetap mempertahankan keserasian dengan lingkungan sekitar. Bentuk dan tinggi bangunan tidak dibuat seolah-olah berbeda sendiri diantara sekitar, tapi tetap memiliki ciri khas sendiri. Desain bangunan memberikan kesan terbuka pada lantai dasar dan permeabilitas. Area plaza (gambar 5) dan taman (gambar 6) menjadi ruang public yang terintegrasi dengan ruang luar dari bangunan. Tujuan lantai dasar dibuat terbuka untuk memaksimalkan konsep openness untuk third place.

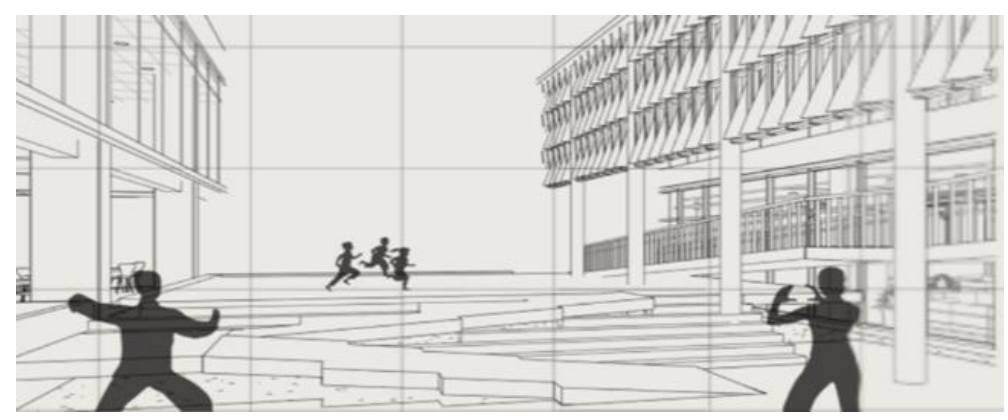

Gambar 5. Area plaza

Sumber: penulis, 2020

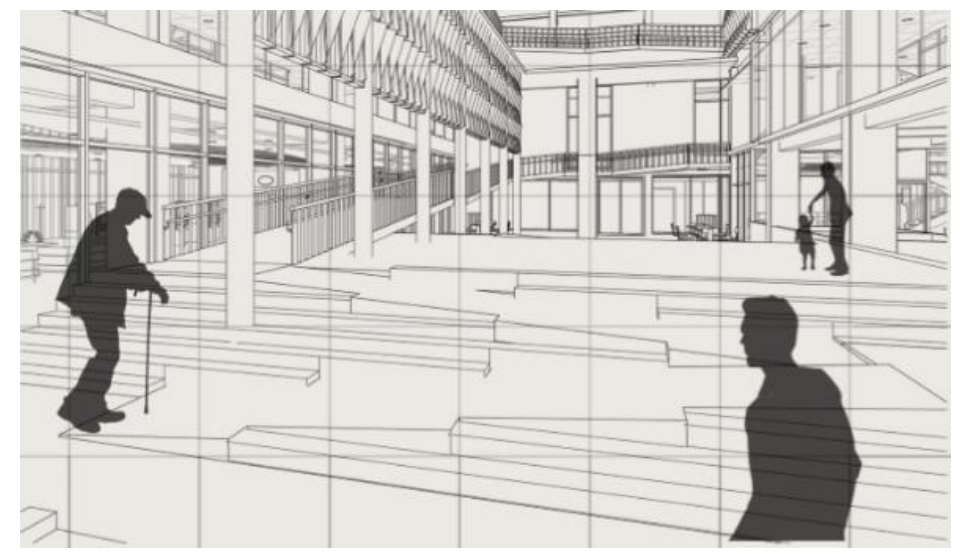

Gambar 6. Area Taman

Sumber: penulis, 2020

Area taman (gambar 8) dan taman menjadi pusat bangunan, dan akan menjadi dominan tempat untuk bertemu oleh pengunjung. Fungsi area ini menjadi sebuah tempat untuk berolahraga dan juga pada area plaza terdapat air mancur yang keluar dari lantai di jam-jam tertentu dan anak-anak bisa bermain-main. 
Pada gambar 7 merupakan salah satu dari kelas/workshop yang disediakan yaitu planting class yang berada pada lantai paling atas. Pada area ini dibuat terbuka karena aktifitas yang ada pada area ini membutuhkan pencahayaan alami dan juga pengudaraan alami, maka dari itu dibuat terbuka. Fasilitas ini juga merupakan fasilitas yang dapat dinikmati dari berbagai level dan juga dapat dinikmati bersama-sama tidak hanya beberapa golongan umur saja. Lalu untuk gambar 8 merupakan area café pada lantai tiga yang dibuat terbuka sehingga terjadi penghawaan alami pada area ini. Pada area ini juga orang-orang dapat bersantai dan berkomunikasi.

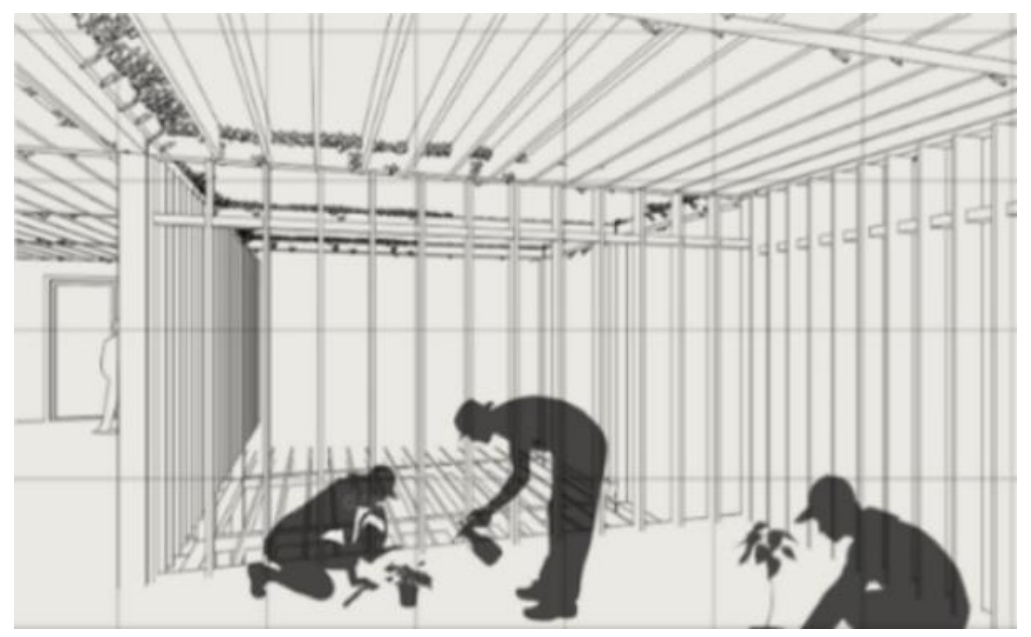

Gambar 7. Painting Class

Sumber: penulis, 2020

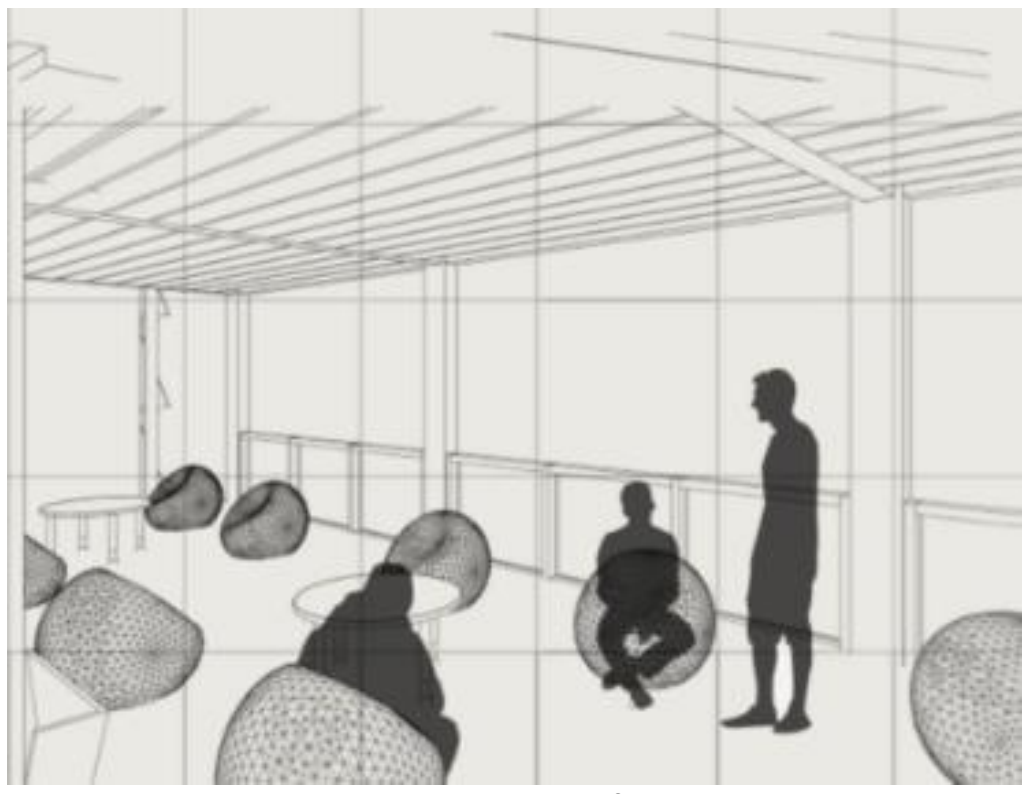

Gambar 8. Cafe

Sumber: penulis, 2020

\section{KESIMPULAN}

Pada proyek ini diharapkan dapat memberi sebuah third place di Kawasan Meruya Selatan agar masyarakat disana memiliki tempat untuk mereka bersosialisasi, melakukan aktifitas, ataupun berelaksasi tanpa harus memperdulikan apa status ekonomi/sosial/budaya, gender, maupun umur mereka. Dan karena Kawasan Meruya Selatan ini di dominasi dengan Kawasan perumahan dan penduduknya sebagian besar bekerja di Jakarta Pusat maka diharapkan mereka yang pulang dari pekerjaannya atau di saat libur dapat menikmati aktifitas dan fasilitas 
dari proyek ini, dan juga tidak hanya kaum muda yang bekerja juga anak-anak, remaja, dan terutama lansia yang jumlahnya juga banyak di Kawasan ini.

Dan karena banyaknya jumlah lansia tiap tahunnya di Kawasan ini, maka proyek ini juga akan dibuat seramah mungkin untuk mereka, seperti penyediaan ruang untuk fasilitas agar mereka lebih produktif, seperti misalnya adanya live music atau bisa menjadi music therapy untuk mereka, kelas untuk belajar music, yoga dan meditasi, dll Selain itu karena proyek ini akan dibuat seramah mungkin untuk kaum lansia maka penggunaan material-material nantinya menggunakan material yang ramah lansia, misalnya lantai yang tidak licin, peletakan railing dalam bangunan dengan bahan yang tidak dingin ketika di pegang (kayu) untuk membantuk mereka yang sulit berjalan. Selain itu juga perlunya di perhatikan jika terdapat koridor, yang sebaiknya minimal $150 \mathrm{~cm}$ karena adanya kemungkinan pengguna lansia menggunakan kursi roda.

\section{REFERENSI}

Ali, H., \& Purwandi, L. (2017). The Urban Middle-Class Millenials Indonesia: Financial and Online Behhavior. Jakarta: PT Alvara Strategi Indonesia.

Butler R.N., \& M.L.Lewis. (1983). Aging and Mental Health . New York: The New America Ink Library, Inc Mosby.

Gallup. (2016). How Millenials Want to Work and Live. Retrieved from enviable workplace: om/wp-content/uploads/Gallup-How-Millennials-Want-To-Work.pdf

Oldenburgh, R. (1989). The Great Place. Da Capo Press.

Sebastian, Y. (2016). Generasi Langgas Millenials Indonesia. Jakarta: Gagas Media.

Setiati, d. (2000). Pedoman Praktis Perawatan Kesehatan (Edisi 1). Jakarta: FK UI.

Badan Pusat Statistik. (2017). Statistik Penduduk Kembangan 2017. https://www.bps.go.id/publication/2018/04/13/7a130a22aa29cc8219c5d153/statistikpenduduk-lanjut-usia-2017.html . Diakses Januari 18 2020)

Badan Pusat Statistik. (2018). Statistik Penduduk Kembangan 2018. (https://www.bps.go.id/publication/2018/12/21/eadbab6507c06294b74adf71/statistikpenduduk-lanjut-usia-2018.html. Diakses Januari 18 2020)

Koran Sindo (2015). Mengenal Generasi Milenial. (https://lifestyle.sindonews.com/berita/1031568/152/mengenal-generasi-millenial. Diakses 6 Febuari 2020) 